\title{
Normas Sociais e Preconceito: O Impacto da Igualdade e da Competição no Preconceito Automático Contra os Negros
}

\author{
Social Norms and Prejudice: The Impact of Egalitarianism and Competition \\ on the Automatic Prejudice Against Blacks
}

\author{
Marcus Eugênio O. Lima ${ }^{a}$, Caliandra Machado ${ }^{b}$, Josele Ávila ${ }^{b}$, Carolina Lima $^{b} \&$ Jorge Vala $^{c}$ \\ ${ }^{a}$ Universidade Federal de Sergipe, São Cristóvão, Brasil, ${ }^{b}$ Universidade Federal da Bahia, Salvador, Brasil, \\ ${ }^{c}$ Universidade de Lisboa, Lisboa, Portugal
}

\begin{abstract}
Resumo
Com o objetivo de analisar o papel dos contextos de resposta no preconceito automático, realizamos três estudos. No primeiro estudo, investigamos os efeitos de dois contextos normativos (igualitário e meritocrático) sobre o preconceito automático contra os Negros. Verificou-se que o contexto meritocrático aumenta o preconceito dos participantes; mas o contexto igualitário não reduz o preconceito. No segundo estudo, investigamos que sentidos as pessoas atribuem à "igualdade". Dois sentidos principais foram encontrados: solidária e formal. Essas duas formas de igualdade foram utilizadas como priming no terceiro estudo, juntamente com contexto meritocrático. Os resultados indicaram que o contexto meritocrático torna os indivíduos mais preconceituosos. No entanto, o contexto da igualdade solidária anulou a ativação automática do preconceito contra os Negros. A igualdade formal situou-se numa posição intermediária entre os dois outros primes. Estes resultados são discutidos à luz das teorias sobre o papel das normas sociais nos processos inconscientes ou automáticos de preconceito.

Palavras-chave: Igualdade; competição; preconceito racial automático.
\end{abstract}

\begin{abstract}
The present studies examined the effects of social norms on the automatic prejudice against Black people. Study 1 assessed the effects of egalitarianism and competitive meritocracy on automatic racial prejudice. The results showed that the competitive meritocracy context increases prejudice. But, the egalitarian context didn't reduce the prejudice. Study 2 investigated the meanings that people assign to "equality". A content analysis denoted two main social representations: equality in the law (Rights and Duties) and equality as solidarity in relationships (fraternity, respect to differences, solidarity, etc.). We named the first representation of equality as "Formal Egalitarianism" and the second as "Solidarity Egalitarianism". Those two forms of equality were used as priming in the third study, together with the competitive meritocracy norm. Results indicated that the competitive meritocracy context increased prejudiced responses. However, the solidarity egalitarianism context controlled the automatic prejudice against Blacks. Formal egalitarianism has no effect on the control of prejudice. These results support the hypothesis concerning the impact of social normative contexts on prejudice activation.

Keywords: Egalitarianism; competitive meritocracy and automatic prejudice.
\end{abstract}

Era madrugada do dia 04 de fevereiro de 1999, Amadou Diallo, 22 anos, imigrante negro da Guiné Bissau, há dois anos residindo nos Estados Unidos, saía do seu apartamento no Bronx para mais uma jornada de 20 horas de trabalho, quando foi abordado por quatro policias brancos da cidade de Nova York. Os policiais, que estavam procurando um estuprador, abordaram Diallo quando este tinha as mãos no bolso. Antes que Diallo pudesse retirar algo do bolso, recebeu 19 tiros dos 41 disparados. Ele tinha na mão apenas um isqueiro de metal quando foi morto. Pouco tempo depois, os quatro policiais acusados foram inocentados. Era 03 de fevereiro de 2004, na Zona Norte de São Paulo, Flávio Ferreira de Sant'Ana, negro,

"Endereço para Correspondência: Universidade Federal de Sergipe - Av. Narechal Rondon, S/N - Dpto. de Psicologia - CEP 49000-000 - São Cristóvão - SE. Fax: (079) 2592021. E-mail:meolima@uol.com.br
28 anos de idade, dentista recém formado, tentava chegar em casa, quando seis policiais militares, que procuravam um assaltante, o abordaram já atirando. Flávio recebeu dois dos sete tiros disparados pelos PMs. Na versão dos policiais, que mais tarde foi refutada pelos fatos, Flávio tinha uma arma na mão e por isso foi morto. Poucos dias depois do assassinato, dois dos policiais envolvidos foram promovidos.

O quê há de comum nos dois casos descritos? Duas mortes por "engano"? A usual truculência da polícia? A impunidade dos crimes? Talvez. Nos depoimentos das famílias e amigos de Flávio e Diallo outro fator aparece: o racismo. Nos dois casos os mortos eram negros, nos dois casos os policiais relataram que se sentiram em perigo e ameaçados e em ambas as situações as vítimas não tiveram o beneficio da dúvida e morreram apenas por serem negros, e portanto, "suspeitos". 
Os dois casos relatados são apenas emblemáticos de vários outros que decorrem de discriminação e violência policial contra os negros (ver dados Fundação Perseu Abamo, 2003) e de racismo da sociedade civil (ver Turra, \& Venturi, 1995). Esses casos parecem indicar que, de uma maneira geral, quando um policial e mesmo um cidadão comum vêem um negro eles não vêem uma pessoa (Flávio ou Diallo), mas vêem um elemento de um grupo amorfo, ao qual associam imediata e inconscientemente o estigma da suspeição e da violência. De tal modo que emerge um preconceito automático, nem sempre consciente que consubstancia atos de discriminação e violência.

$\mathrm{Na}$ Psicologia Social, muitos estudos têm investigado fenômenos como este, que se inserem no âmbito dos processos automáticos ou não controlados de estereotipia e de preconceito; e que, em função das pressões sociais contra as manifestações públicas de preconceito e racismo, têm crescido em importância nas duas últimas décadas. Com efeito, os processos automáticos têm se tornado um dos principais temas nos trabalhos sobre atitudes e estereótipos de maneira geral (Bargh, 1989, 1994), e sobre o preconceito de maneira particular (Devine, 1989; Dovidio, 2001). Numa pesquisa sobre os artigos publicados em cognição social feita por Greenwald e Banaji (1995), verifica-se que $13 \%$ dos textos incluíam medidas de cognições implícitas. Além disto, o Journal of Personality and Social Psychology, um dos principais jornais em Psicologia Social, dedicou em Novembro de 2001, um número exclusivo aos processos automáticos de preconceito.

Ainda que, na psicologia social, muitos estudos analisem os processos automáticos associados ao preconceito; a grande maioria desses trabalhos concentra-se exclusivamente na identificação e análise dos fatores intrapsíquicos (processos cognitivos e motivacionais) subjacentes à suposta automaticidade do preconceito. Poucos são os estudos que analisam o papel das normas sociais e das ideologias (fatores interpessoais e intergrupais) na construção de imagens e representações cognitivas preconceituosas contra membros de grupos minoritários. Noutros termos, poucos estudos analisam porque os negros estão automaticamente associados à violência e à negatividade na nossa sociedade, e em que contextos essas associações emergem com mais ou menos força.

Ademais, cabe referir que a bibliografia produzida sobre a automaticidade dos estereótipos e do preconceito, boa parte dela referida neste trabalho, é eminentemente norte-americana. Não conhecemos nenhum estudo que tenha analisado essa problemática no Brasil.

Este trabalho procura analisar o papel das normas sociais, especificamente das normas da igualdade e da competição individualista, no preconceito automático contra os Negros.

\section{Processos Automáticos de Preconceito}

Os processos automáticos podem ser definidos como aqueles que acontecem sem a intenção consciente do ator: "Automatic activation processes are those which may occur without intention, without any conscious awareness and without interference with other mental activity" (Posner \& Snyder, 1975 , p. 81). De acordo com Bargh (1994), os processos automáticos podem ser definidos em termos de quatro atributos: consciência, não eficiência, intencionalidade e controlabilidade. A automaticidade do processo seria resultado da ausência de pelo menos uma destas quatro características que tornam o processamento da informação controlado (ver Wegner, \& Bargh, 1998, para uma revisão).

A existência de ativação automática dos estereótipos e do preconceito tem sido verificada na psicologia em um amplo conjunto de estudos. Estes estudos utilizam os dois paradigmas dominantes na análise dos processos automáticos, a latência de resposta e o priming ${ }^{1}$.

\section{Evidências do Preconceito Automático: Os Paradigmas \\ do Priming e da Latência de Resposta}

Um amplo conjunto de estudos demonstra que um priming "racial" ou "étnico" produz facilitação estereotípica (i.e., reconhecimento mais rápido de itens relativos aos estereótipos dos grupos depois do priming). Em quase todos esses estudos a variável dependente é a latência de resposta a determinados estímulos. Especificamente, alguns estudos demonstram que participantes submetidos a um priming relacionado com a categoria social "Negros" demoram mais tempo para reconhecer palavras ou associações positivas e são mais rápidos para reconhecerem palavras ou associações negativas, seja quando o priming foi categorial, como por exemplo o próprio rótulo "Negros" apresentado de modo subliminar (e.g., Wittenbrink, Judd, \& Park, 1997, 2001a), ou de modo supraliminar (e.g., Devine, 1989; Gaertner, \& McLaughlin, 1983); seja quando o priming foi uma fotografia ou um desenho representativo de uma pessoa Negra apresentada de maneira supraliminar (e.g., Fazio, Jackson, Dunton, \& Williams, 1995) ou de maneira subliminar (e.g., Bargh, Chen, \& Burrows, 1996; Dovidio, Kawakami, Johnson, Johnson, \& Howard, 1997).

Independentemente das variações nas formas de analisar a ativação automática do preconceito, todos estes estudos constatam que um priming associado à categoria "Negros" (e.g., fotos de membros do grupo, rótulos categoriais ou estereótipos do grupo) facilita ou desencadeia de modo automático ou involuntário a estereotipia e o preconceito negativo contra os Negros.

Uma das técnicas mais utilizadas para analisar o preconceito automático é o Implicit Association Test (IAT), desenvolvido por Greenwald, McGhee e Schwartz (1998). Este teste analisa especificamente as "atitudes raciais implícitas" dos indivíduos.

\section{O IAT e o Preconceito Implícito}

Greenwald e Banaji (1995) afirmam que algumas atitudes, "atitudes implícitas", podem ser expressas fora do con- 
Lima, M.E.O., Machado, C., Ávila, J., Lima, C., \& Vala, J. (2006). Normas Sociais e Preconceito: O Impacto da Igualdade e da Competição no Preconceito Automático Contra os Negros.

trole da consciência dos indivíduos. Para estes autores as atitudes raciais são um desses casos de atitudes implícitas, e podem ser definidas como conseqüências de experiências passadas, sobre os quais temos pouca ou nenhuma consciência, mas que dão corpo a sentimentos e comportamentos, favoráveis ou desfavoráveis, contra determinados grupos ou pessoas ${ }^{2}$.

Com base nesses pressupostos Greenwald et al. (1998) criam o Implicit Association Test (IAT), uma técnica cujo objetivo é aferir preconceitos implícitos.

O IAT é uma técnica que permite analisar atitudes raciais implícitas através da associação de um determinado conceito ou categoria-alvo com uma dimensão de atributos. O IAT é composto por cinco fases. Na primeira fase, definida como initial target concept, os participantes devem indicar se um determinado objeto ou nome pertence a uma determinada categoria (e.g., nomes ou fotos de pessoas negras ou nomes ou fotos de pessoas brancas devem ser incluídos nas categorias "Negros" ou "Brancos"). Na segunda fase os participantes devem classificar palavras em categorias de "coisas agradáveis" ou de "coisas desagradáveis". A terceira fase é já uma fase de associação da categoria de atributos com os alvos da discriminação. De modo que aparece à esquerda do monitor de um computador uma associação da categoria de atributos com a categoria alvo de discriminação (e.g., pessoas negras ou coisas agradáveis), enquanto que do lado direito aparece a outra associação (pessoas brancas ou coisas desagradáveis). A quarta fase consiste na inversão da posição das categorias da primeira fase (initial target concept), ou seja, os rótulos categoriais "Negros" e "Brancos", por exemplo, aparecem no monitor em posição contrária à que haviam aparecido na primeira fase. Por fim, na quinta fase, a associação apresentada na terceira fase é invertida, isto é, do lado esquerdo do monitor aparece: "pessoas brancas ou coisas agradáveis"; enquanto que do lado direito aparece: "pessoas negras ou coisas desagradáveis". A variável dependente em questão é a latência de resposta no reconhecimento do alvo quando associado a coisas agradáveis e quando associado a coisas desagradáveis. Greenwald et al. (1998) definem as duas fases de associação como "associações compatíveis", quando a associação é a mais comum na população pesquisada (e.g., "flores ou coisas agradáveis", "americanos brancos ou coisas agradáveis") e "associações incompatíveis” (e.g., "insetos ou coisas agradáveis", "americanos negros ou coisas agradáveis"). O efeito IAT, indicador de preconceito automático, é obtido através da subtração das associações "incompatíveis" das "compatíveis".

Greenwald et al. (1998) realizaram uma investigação com estudantes universitários norte-americanos brancos, na qual os participantes deveriam colaborar numa tarefa de reconhecimento de nomes de pessoas brancas e nomes de pessoas negras associados a coisas agradáveis e a coisas

\footnotetext{
2 "Introspectively unidentified (or inaccurately identified) traces of past experience that mediate favorable or unfavorable feeling, thought, or action toward social objects" (Greenwald \& Banaji, 1995, p. 8).
}

desagradáveis. Os resultados deste estudo indicam uma preferência atitudinal implícita para os brancos em relação aos negros, manifesta através da maior velocidade de resposta às associações "compatíveis" (i.e., brancos + atributos positivos e negros + atributos negativos) do que às associações "incompatíveis" (i.e., negros + atributos positivos e brancos + atributos negativos). Mais recentemente, Devine, Plant, Amodio, Harmon-Jones e Vance (2002) obtiveram resultados semelhantes, também nos EUA, e utilizando o mesmo paradigma, ainda que com algumas variações.

\section{Atitudes Raciais Implícitas e Normas Sociais}

Seguindo o argumento principal dos estudos referidos, podemos considerar que as associações preconceituosas automáticas são um resultado das experiências passadas, que se expressa fora da consciência e do controle voluntário dos indivíduos. Todavia, podemos indagar, por exemplo, que experiências passadas a maior parte das pessoas teve com os Aborígines da Austrália, ou com os Maori da Nova Zelândia, ou com os Índios do Brasil, com os Negros, os Árabes, os Protestantes, os Muçulmanos, os Homossexuais, as Mulheres, etc., que justifiquem a criação de associações negativas automáticas contra essas categorias sociais.

Muzafer Sherif (1967), num trabalho clássico na psicologia social no qual analisa conflito e cooperação nas relações entre grupos, argumenta que o preconceito pode ser dirigido contra grupos sobre os quais nada conhecemos e mesmo contra grupos que nunca vimos ou mantivemos relações. Pois, continua Sherif, os estereótipos e o preconceito contra um determinado grupo resultam muito mais da nossa relação com os membros do nosso grupo do que da nossa relação com os membros de um grupo estigmatizado.

Seguindo esta linha de pensamento, podemos afirmar que são as normas sociais ou ideologias, no sentido de Dubois (2003), que definem a direção e o conteúdo do preconceito numa sociedade (Lima \& Vala, 2004a). As normas sociais são aqui definidas como regras explícitas e implícitas que descrevem e prescrevem comportamentos (Sherif, 1967).

O pioneiro no estudo da influência das normas sociais sobre os processos psicológicos foi Sherif (1936), com os experimentos sobre o efeito auto-cinético. Sherif verifica que os indivíduos necessitam de padrões e referências para fazerem as suas avaliações e julgamentos, e que quando em uma situação coletiva é o grupo que fornece essas referências. É neste sentido que, nos anos 50, os aspectos estratégicos do preconceito começam a ser destacados.

Em 1952, Minard realiza um estudo sobre racismo em minas de carvão nos EUA, e verifica que os mineiros brancos discriminavam os colegas negros fora das minas: nas ruas, nos bares, etc. Mas, dentro das minas a discriminação racial desaparecia. No final desta mesma década, Thomas Pettigrew (1958), estudando relações racializadas nos EUA do Jim Crow e na África do Sul do Apartheid, realiza as principais análises empíricas sobre o papel das 
normas ou contextos socioculturais no racismo. Pettigrew verifica que as expressões de racismo nesses dois países refletem muito mais as pressões das normas culturais para a discriminação do que fatores relacionados com personalidade dos atores sociais.

A partir dos anos 70, com a ênfase nos processos cognitivos subjacentes ao preconceito (ver Duckitt, 1992), o papel das normas sociais é secundarizado nas análises psicossociais do preconceito e do racismo, em favor da ênfase nos processos cognitivos e motivacionais implicados nos estereótipos e no preconceito. Esse interesse ressurge na atualidade, com, por exemplo, Crandall, Eshleman e O’Brien (2002), que realizam uma investigação exaustiva sobre os efeitos das normas sociais no preconceito.

Embora esses estudos sinalizem para a importância das normas sociais na expressão do preconceito e do racismo, nenhum deles especifica que normas sociais atuam diretamente sobre a produção e inibição desses fenômenos. Alguns estudos, no entanto, têm se preocupado com esta questão. Novamente nesta seara Sherif é pioneiro. Sherif e Sherif (1953), no estudo clássico intitulado "a caverna dos ladrões”, foram os primeiros a demonstrar empiricamente que um contexto social de competição pode produzir conflito e preconceito intergrupal. Mais recentemente, outros estudos têm encontrado uma relação positiva entre a adesão aos valores da competição, da ética protestante, da meritocracia e do individualismo com o preconceito e com racismo (e.g., Correia, Brito, Vala, \& Perez, 2001; Katz, \& Hass, 1988; Lima, \& Vala, 2002, 2004b; Schwartz, 1996; Vala, Brito, \& Lopes, 1999; Vala, Lima, \& Lopes, 2002, ver Lima, 2003, para uma revisão).

Parece que o mecanismo sócio-cognitivo que define os efeitos do individualismo e da competição no preconceito e no racismo refere-se à necessidade de justificação da situação social e econômica dos grupos e à crença de que as pessoas recebem o que merecem. Essas crenças são centrais na definição do Individualismo e da Meritocracia que caracterizam a competição e podem ser definidas como "ideologias legitimadoras" (Major, Gramzow, McCoy, Levin, Schmader \& Sidanius, 2002).

Todavia, se as normas do individualismo e da competição produzem resultados consistentes no que concerne à produção e deflagração de preconceitos e de racismo, que outras normas sociais produzem efeito contrário, ou seja, reduzem o preconceito e o racismo?

Vários estudos têm verificado que são as normas da igualdade e do humanitarismo as responsáveis pela redução do viés endogrupal num paradigma mínimo (e.g., Hertel, Aart, \& Zeelenberg, 2002; Hertel, \& Kerr, 2001; Jetten, Spears, \& Manstead, 1996), pela redução do preconceito e do racismo (e.g., Katz, \& Hass, 1988) e pela inibição dos estereótipos ou da despersonalização de alvos minoritários em tarefas de formação de impressão (e.g., Goodwin, Gubin, Fiske, \& Yzerbyt, 2000; Lima, \& Vala, no prelo). Com efeito, o simples fato de levar as pessoas a pensarem sobre a igualdade e produzirem argumentos sobre este tema diminui a discriminação e aumenta o comportamento pró-social (Maio, Olson, Allen \& Bernard, 2001).
Com base nesses pressupostos, o objetivo desta pesquisa é analisar o papel que dois contextos (igualitário e competitivo meritocrático) têm na ativação automática do preconceito contra os Negros. As nossas principais hipóteses são: (a) existe preconceito automático contra os Negros e (b) esse preconceito é influenciado pelas normas ou contextos de resposta, na seguinte direção: (i) a norma da competição/meritocracia ativa o preconceito automático contra os negros e (ii) a norma igualitária inibe a ativação automática de preconceito contra os negros.

Para testar essas hipóteses realizamos três estudos nos quais levamos as pessoas a pensarem sobre a igualdade ou sobre a competição e em seguida analisamos os níveis de preconceito automático dos participantes, por meio do Teste de Associações Implícitas (IAT). No primeiro estudo investigamos os efeitos de dois tipos de contextos normativos (igualitário e da competição) e de um contexto neutro ou condição controle (crença em vida extraterrestre) sobre o preconceito automático contra os Negros. No estudo dois analisamos as representações sociais da igualdade. No terceiro estudo construímos dois tipos de contextos normativos igualitários (formal e solidário), que junto com o contexto da meritocracia competitiva, permitiram analisar o impacto dessas normas no preconceito automático contra os Negros.

\section{Estudo 1}

Nesse estudo procuramos investigar o papel das normas sociais no preconceito automático contra os Negros.

\section{Método}

\section{Amostra e procedimentos.}

Os participantes foram 35 estudantes universitários brancos ${ }^{3}$ de uma universidade privada em Aracaju; sendo 15 homens e 20 mulheres. Os participantes foram convidados a colaborar em 3 estudos independentes. Foram informados que o primeiro estudo consistia numa tarefa de formulação de argumentos, na qual deveriam ler um texto e formular razões sobre a importância do tema. Esta foi a fase de priming. Este procedimento, semelhante ao utilizado por Maio, Olson, Allen e Bernard (2001), tem simplesmente o objetivo de levar os participantes a pensarem durante algum tempo sobre um determinado tema social. Cada um dos participantes dispunha de 8 minutos nesta fase. Terminado este tempo o aplicador solicitava ao participante que relesse seus argumentos, pois eles seriam instados a lembrar alguns deles mais tarde. A finalidade deste procedimento foi a de fazer com que o priming permanecesse ativo nas tarefas posteriores. O número médio de argumentos ou razões produzidas pelos participantes foi de $3.72(D P=1.48)$. 
Lima, M.E.O., Machado, C., Ávila, J., Lima, C., \& Vala, J. (2006). Normas Sociais e Preconceito: O Impacto da Igualdade e da Competição no Preconceito Automático Contra os Negros.

$\mathrm{Na}$ segunda fase os participantes foram convidados a colaborar num estudo sobre a categorização de estímulos ao computador. Esta fase consistiu numa versão do IAT que emparelha fotografias de rostos de pessoas Negras e Brancas com palavras positivas e com palavras negativas. Utilizamos 12 fotografias em tamanho $5.3 \mathrm{~cm} \mathrm{X} 4 \mathrm{~cm}$; sendo 6 de pessoas brancas e seis de pessoas negras, seis de pessoas de sexo masculino e seis de pessoas de sexo feminino. As pessoas retratadas nas fotos estavam todos numa mesma faixa etária (20 a 25 anos). Utilizamos também 16 palavras sem conteúdo estereotípico, sendo oito positivas (paz, alegria, sorriso, amor, prazer, amizade, satisfação e beleza) e oito de sentido negativo (ódio, guerra, triste, horrivel, cruel, fracasso, terrivel e agonia). As fotografias utilizadas e os procedimentos foram idênticos aos de Greenwald et al. (1998) ${ }^{4}$, apenas traduzimos as palavrasestímulo.

No primeiro bloco do IAT as 12 fotos apareciam uma a cada vez no centro da tela e os participantes deveriam indicar se a pessoa da foto era branca ou negra. Foram feitas 20 apresentações em ordem aleatória. No segundo bloco os participantes deveriam indicar se as palavras eram positivas ou negativas. Cada uma das 16 palavras aparecia no cento do computador e lá permanecia até que o participante indicasse sua valência. Neste bloco houve 20 exibições aleatórias. No terceiro e no quinto blocos (tarefas de associação) as 16 palavras e as 12 fotos apareciam de maneira alternada e a tarefa dos participantes era indicar se o que viam no centro da tela era algo positivo ou negativo. Em cada um destes dois blocos utilizamos 60 apresentações em ordem aleatória. No quar to bloco novamente apareciam as 12 fotos e os participantes deveriam indicar se o que viam era uma pessoa negra ou branca. Novamente 20 apresentações foram feitas. O total de apresentações de estímulos para cada participante durante o experimento foi, portanto, de 180 .

Finalmente, na terceira fase, os participantes foram solicitados a lembrarem os argumentos formulados na primeira fase. Todos os participantes lembraram a idéia geral dos seus argumentos.

\section{Material e delineamento.}

O IAT foi administrado num laptop Pentium, cujo monitor possui 15 polegadas e 1024 x 768 pixels e $60 \mathrm{~Hz}$., de freqüência de atualização. Utilizamos um delineamento 3 (Priming: meritocracia competitiva/Igualitário/Neutro) X 2 (preconceito: Latência nas associações "compatíveis" vs. Latência nas associações "incompatíveis"). A primeira variável foi uma inter-participantes e a segunda uma intraparticipantes. Os 35 sujeitos foram distribuídos aleatoriamente pelas três condições experimentais, em grupos de 11,11 e 13 participantes.

" O estudo replicado pode ser encontrado na Internet no endereço http://bulster.cs.yale.edu/implicit
Priming ou Contextos de Resposta

\section{Contexto da igualdade}

Podemos imaginar muitas razões para que todas as pessoas sejam tratadas de maneira igualitária. Por exemplo, podemos pensar que as pessoas são todos seres humanos e que devem, em conseqüência, ser tratadas como iguais. Se todas as pessoas são iguais perante a lei, então todas, sem nenhum tipo de distinção, merecem oportunidades iguais para viverem. Podemos pensar ainda que a Igualdade entre todos é fundamental para o desenvolvimento da sociedade. Gostaríamos agora que pensasse sobre o que acabou de ler e que escrevesse argumentos que justifiquem a importância da igualdade entre as pessoas. Procure organizar os seus pensamentos e indique o máximo de razões que consiga, escrevendo-as na página seguinte.

\section{Contexto da meritocracia competitiva}

Podemos imaginar muitas razões para que as pessoas tenham uma formação profissional com ênfase no mérito, na competência e na máxima produtividade no trabalho. Podemos considerar que uma sociedade que não valorize a competição terá muitos problemas para desenvolver-se, uma vez que é a livre concorrência entre os indivíduos que maximiza o desenvolvimento. Um indivíduo disposto a trabalhar muito, auto-disciplinado e eficiente terá muitas chances de ser bem sucedido e realizado, desde que o seu mérito seja respeitado. Gostaríamos agora que pensasse sobre o que acabou de ler e que escrevesse argumentos que justifiquem a importância da competição e da valorização do mérito individual. Procure pensar sobre o tema e indicar o máximo de razões que consiga, escrevendo-as na página seguinte.

\section{Contexto neutro}

Podemos imaginar muitas razões para que exista vida para além do Planeta Terra. Várias pessoas afirmam ter visto seres extraterrestres. Existem provas da existência destas formas de vida. Recentes descobertas têm demons-trado que existem condições de vida em outros planetas e que, portanto, eles podem ter sido habitados. Além disto, o nosso conhecimento sobre as possibilidades de vida extraterrestre limita-se à Via Láctea, mas existem inúmeros outros planetas que, distantes da Terra, podem ser habitados. Gostaríamos agora que pensasse sobre o que acabou de ler e que escrevesse argumentos que justifiquem a possibilidade de que haja vida extraterrestre. Procure organizar os seus pensamentos e indique o máximo de razões que consiga, escrevendoas na página seguinte.

\section{Resultados e Discussão}

Antes da análise dos resultados seguimos os procedimentos sugeridos por Greenwald et al. (1998). Assim, para evitar distorções na distribuição normal, todas as médias foram logaritimizadas para as análises estatísticas, mas nos 
quadros apresentamos as médias não transformadas. As latências inferiores a 300 milésimos de segundos (ms.) e superiores a 3000 ms., foram substituídas por 300 e 3000 ms., respectivamente. No total foram feitas 133 substituições num universo de 4200 apresentações (120 apresentações nas tarefas de associação para cada um dos 35 participantes), o que implicou em 2,9\% de respostas substituídas.

Primeiramente analisamos se havia efeitos do priming sobre o número de razões produzidas. Os resultados de uma ANOVA One-Way indicam que não, $F(2,34)=1.32, p$ $=.28$. Em seguida testamos se havia algum efeito do gênero sobre a ativação automática do preconceito. Para tanto, realizamos uma Análise de Variância com medidas repetidas, considerando o priming (Igualitário/Meritocracia Competitiva/Neutro) como variável inter-participantes e o tipo de associação ("Compatíveis" vs. "Incompatíveis") como variável independente intra-participantes. A variável dependente foi a latência ou o tempo para reconhecer os estímulos. Os resultados indicam que o efeito do gênero sobre o preconceito automático contra os Negros não foi significativo, $F(1,32)=1.78, n s$.

Para avaliarmos nossas hipóteses realizamos uma ANOVA com medidas repetidas, tomando o priming como variável inter-participantes e o tipo de associação (“com- patíveis" vs. "incompatíveis") como variável independente intra-participantes. A variável dependente foi a latência de resposta. Verificamos que não existe um efeito principal do priming, $F(2,32)<1$, ns. Entretanto, o efeito principal do tipo de associação (efeito IAT) foi significativo, $F$ (1, $32)=26.32, p<.001$. Como podemos ver na Tabela 1 , esse efeito indica, em consonância com os pressupostos de Greenwald e Banaji (1995) e com os resultados de Greewald et al. (1998), que as associações "compatíveis" (Brancos + Coisas Positivas vs. Negros + Coisas Negativas) são reconhecidas mais rapidamente $(M=1089.20 \mathrm{~ms}$. $D P=343.97 \mathrm{~ms}$.) do que as associações "incompatíveis" (Negros + Coisas Positivas vs. Brancos + Coisas Negativas) $(M=1263.31 \mathrm{~ms} . D P=269.96 \mathrm{~ms}$. $)$.

Todavia, em consonância com as nossas hipóteses, este efeito foi moderado por uma interação com o contexto normativo, $F(2,32)=4.74, p=.01$. O efeito IAT (menor latência nas associações "compatíveis" do que nas "incompatíveis") ocorre apenas no contexto da Meritocracia Competitiva. Neste contexto ocorreu ainda uma menor latência de resposta nas associações "compatíveis" do que na condição controle (contexto Neutro) e do que no contexto Igualitário. Estes contextos, por sua vez, não se diferenciaram (ver Tabela 1).

Tabela 1

Médias e Desvios Padrões (nos parêntesis) da Latência de Resposta (em milésimos de segundos) nas Associações "Compatíveis" e "Incompativeis" em Função do Priming $(n=35)$

\begin{tabular}{lll}
\hline Priming/Contexto & Associações Incompatíveis & Associações Compatíveis \\
\hline Meritocracia Competitiva & $1311.60_{a}$ & $996.19_{\mathrm{b}}$ \\
& $(279.98)$ & $(242,56)$ \\
\hline Igualitário & $1238.98_{\mathrm{ac}}$ & $1094.47_{\mathrm{c}}$ \\
& $(276.14)$ & $(282.38)$ \\
\hline Neutro & $1239.36_{\mathrm{ac}}$ & $1176.96_{\mathrm{ac}}$ \\
& $(276.92)$ & $(445.36)$ \\
\hline Total & 1263.31 & 1089.20 \\
\hline
\end{tabular}

Nota. Médias com letras diferentes são significativamente diferentes (Student Newman-Keuls, $p<.05)$.

Para tornar a visualização dos resultados mais clara, calculamos o efeito IAT, subtraindo o tempo de reconhecimento das associações "incompatíveis" do tempo para reconhecer as associações "compatíveis". Em seguida, para verificarmos em que condições ocorria preconceito automático contra os Negros, realizamos testes $\mathrm{t}$ de Student tomando o valor zero (ausência de preconceito) como critério. Os resultados indicam que ocorre preconceito nas três condições de resposta ${ }^{5}$, isto é, nos três contextos há uma diferença significativa entre o escore obtido de preconceito automático e o valor zero (ver Figura 1).

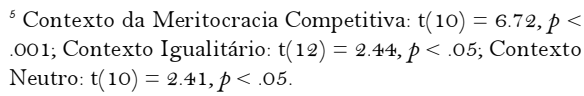

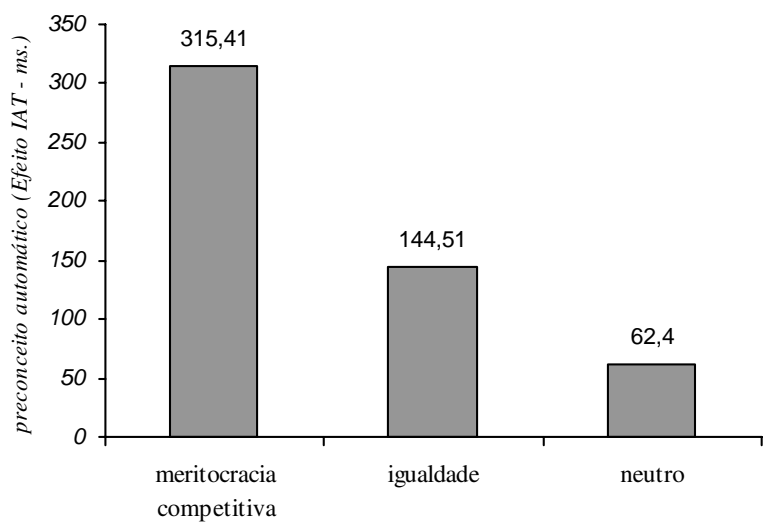

Figura 1. Efeito IAT (latência de resposta para as associações "incompatíveis" - latência de resposta para as associações compatíveis). 
Lima, M.E.O., Machado, C., Ávila, J., Lima, C., \& Vala, J. (2006). Normas Sociais e Preconceito: O Impacto da Igualdade e da Competição no Preconceito Automático Contra os Negros.

Estes resultados confirmam parcialmente as nossas hipóteses, uma vez que a norma da competição produz preconceito automático contra os Negros. Entretanto, diferentemente do esperado, a norma do Igualitarismo não foi efetiva na anulação do preconceito automático. Mesmo não sendo estatisticamente significativo, a condição Neutra implicou em menor ativação automática do preconceito do que a condição Igualitária. Embora, nas três condições tenha havido preconceito automático. Esperávamos que o padrão de resultados fosse inverso, ou seja, que na condição Neutra houvesse uma tendência ao preconceito automático, que se intensificaria na condição de competição e que seria anulada pela norma do Igualitarismo.

Assim, com base nesses dados parece que apenas pensar sobre a competição e o mérito individual torna os indivíduos mais preconceituosos numa tarefa posterior; ao passo que pensar sobre a igualdade ou sobre vida extraterrestre produz efeitos idênticos sobre a inibição da ativação automática do preconceito, inócuos em ambos os casos. Hertel e Kerr (2001), num estudo sobre viés endogrupal, também verificam um efeito pouco efetivo da igualdade na redução do preconceito. Katz e Hass (1988), num estudo sobre preconceito ambivalente, verificam que o efeito da norma da igualdade é mais fraco do que esperado.

Esse padrão de resultados aponta a ineficiência da igualdade, tomada num sentido geral, no controle do preconceito automático. Será, no entanto, que existe alguma isomorfia quando as pessoas pensam sobre a igualdade, ou será, pelo contrário, que a igualdade possui sentidos diferentes para as pessoas?

Numa perspectiva sociológica, Michel Wieviorka (2002) faz uma diferenciação importante entre igualdade, definida em termos formalistas como igualdade de oportunidades; e equidade, definida como um conjunto de estratégias que permitam aos grupos desfavorecidos competirem em igualdade de condições com os mais favorecidos. Para Wieviorka a Igualdade é um fim em si mesma, enquanto que a Equidade é um meio de acesso a uma igualdade real e não apenas formal.

A diferenciação entre igualdade e equidade é clássica na filosofia. Para Aristóteles a equidade é um "apelo à justiça voltado à correção da lei em que a justiça se exprime. A equidade possui uma natureza de retificação da lei no que esta se revele insuficiente pelo seu caráter universal" (Abbagnano, 1998, p. 340).

Essa reflexão nos auxilia na formulação de uma hipótese interpretativa para compreensão do padrão de resultados obtidos. Podemos supor que a norma da igualdade possui uma ambivalência ou contradição interna na nossa cultura. Por um lado, a igualdade pode ser percebida em termos de solidariedade e de integração entre os grupos, à semelhança do conceito de equidade de Wieviorka; por outro lado, a igualdade pode ser entendida enquanto um conjunto prévio de condições fundamentais para tornar legitima uma disputa ou competição (igualdade de oportunidades ou de direitos). Neste caso, a igualdade ao invés de reduzir o preconceito pode alimentá-lo, uma vez que atua como uma ideologia ambígua e, ao mesmo tempo, legitimadora das assimetrias sociais (Billig, 1984).

A fim de testarmos esta hipótese realizamos um segundo estudo, no qual tentamos encontrar um priming ou contexto igualitário mais efetivo. Para tanto, pesquisamos os sentidos que pessoas atribuem à igualdade.

\section{Estudo 2}

Partindo do pressuposto de que a norma ou o valor da igualdade é fundamental na formulação de políticas públicas e mesmo de estratégias não institucionais para a superação do preconceito e da discriminação, consideramos importante analisar que sentidos esta norma pode ter. Assim o objetivo deste estudo é o de analisar os sentidos da igualdade.

\section{Método}

\section{Amostra e procedimentos.}

Foram entrevistados 35 estudantes universitários de vários cursos da Universidade Federal da Bahia, sendo 30 de sexo feminino e cinco de sexo masculino. A idade dos entrevistados variou de 19 a 50 anos $(\mathrm{M}=23.77$, $\mathrm{DP}=$ 6.93). Com relação à cor da pele, 13 estudantes foram classificados como não brancos (negros ou "pardos") e 22 como brancos. Os participantes foram contatados em sala de aula e convidados a responder à pergunta: "Para você o que é a igualdade?"

\section{Resultados e Discussão}

Os resultados indicam que a igualdade é entendida em pelo menos dois sentidos gerais. Um primeiro sentido refere uma igualdade formalista ou constitucional, formada por respostas em termos de "igualdade de direitos e de deveres". Esta categoria de resposta foi dominante, totalizando 20 enunciações. Um outro conjunto de respostas refere uma igualdade social ou nas relações com os outros. Esse tipo de percepção da igualdade foi expresso nas respostas da igualdade em termos de solidariedade (2 enunciações), igualdade como não preconceito (5 enunciações), igualdade como cidadania (3 enunciações) e igualdade como respeito às diferenças ( 1 enunciação) (ver Tabela 2). Consideramos este conjunto de percepções da igualdade como ocupando um campo semântico próximo ao conceito de eqüidade e, por isto, denominaremos esta concepção de "igualdade solidária" em oposição á "igualdade formal" expressa na primeira e mais freqüente categoria de resposta. 
Tabela 2

Representações Sociais da Igualdade Ancoradas na Pertença Étnica (3 enunciações)

\begin{tabular}{lc}
\hline O que é a igualdade? & Total \\
\hline Direitos e deveres iguais a todos & 20 \\
Viver em solidariedade & 2 \\
Não preconceito, não exclusão e não discriminação & 5 \\
Cidadania & 3 \\
Respeito às diferenças & 1 \\
Não responde ou não categorizáveis & 4 \\
\hline Total & 35 \\
\hline
\end{tabular}

Esses resultados permitem concluir que existem maneiras diferentes de conceber a igualdade. Pensamos que diferentes representações da igualdade podem engendrar diferentes crenças, atitudes e comportamentos nas relações raciais. Esses dados nos levaram a realizar um terceiro estudo, cujo objetivo foi analisar os efeitos da igualdade solidária, da igualdade formal e da meritocracia competitiva no preconceito automático contra os Negros.

\section{Estudo 3}

Neste terceiro estudo esperamos que o contexto da meritocracia competitiva implique em preconceito automático, que haja também, ainda que em menor grau, preconceito automático no contexto da igualdade formal, e que o contexto da igualdade solidária anule a ativação automática do preconceito contra os Negros.

\section{Método}

\section{Amostra e procedimentos}

Participaram deste estudo 35 estudantes da área de ciências humanas da UFBA, 60\% de sexo feminino. As idades variaram de 18 a 30 anos $(\mathrm{M}=22.29, \mathrm{DP}=3.11)$. Dos 35 participantes, 10 foram definidos como não brancos ("pardos" e negros) e 25 como brancos. Os procedimentos foram idênticos aos do estudo 1, com uma diferença importante: neste estudo procedemos a uma alteração no priming. Seguindo os resultados do estudo 2 , criamos dois primes para a Igualdade ${ }^{6}$ e mantivemos idêntico o prime da Meritocracia Competitiva, não utilizamos o prime neutro ou condição controle. Neste estudo o número médio de razões ou argumentos oferecidos pelos participantes foi $2.66(\mathrm{DP}=1.21)$.

\section{Delineamento}

Utilizamos um delineamento 3 (Priming: Competição Individualista/Igualitário Solidário/Igualitário Formal) X 2 (preconceito: Latência nas associações "compatíveis" vs. Latência nas associações "incompatíveis"). A primeira variável foi uma inter-participantes e a segunda uma intra-

\footnotetext{
${ }^{6} \mathrm{O}$ priming da Igualdade Formal foi o mesmo do Estudo 1.
}

participantes. Os 35 sujeitos foram distribuídos aleatoriamente pelas três condições experimentais, em grupos de 12, 12 e 11 partcipantes.

\section{Prime ou Contexto da Igualdade Solidária}

Podemos imaginar muitas razões para que todas as pessoas sejam tratadas de maneira igualitária. Por exemplo, podemos pensar que todas as pessoas devem ter as suas diferenças respeitadas e valorizadas pela sociedade. E que as diferenças entre as pessoas não devem produzir diferenciações ou discriminações e preconceitos. Isto implica pensar uma sociedade mais inclusiva e justa que produza integração entre as pessoas e crie uma situação de igualdade e solidariedade entre todos. Gostaríamos agora que pensasse sobre o que acabou de ler e que escrevesse argumentos ou razões que justifiquem a importância da igualdade entre as pessoas. Procure pensar sobre o tema e indicar o máximo de razões que consiga, escrevendo-as na página seguinte.

\section{Resultados e Discussão}

Assim como no primeiro estudo, antes da análise dos resultados seguimos os procedimentos sugeridos por Greenwald et al. (1998). As médias foram logaritimizadas para as análises estatísticas e as latências inferiores a 300 e superiores a $3000 \mathrm{~ms}$., foram substituídas por 300 e 3000 ms., respectivamente. No total foram feitas 362 substituições num universo de 4200 apresentações experimentais, o que implicou em 8,6\% de respostas substituídas.

Em seguida, analisamos se havia efeitos do contexto de resposta sobre o número de razões produzidas. Os resultados de uma ANOVA One-Way indicam que o efeito do priming sobre o número de argumentos não foi significativo, $F(2,34)=1.69, p=.20$. Os resultados indicam que não houve efeito significativo nem do gênero, $F(1,32)=1.26$, $n s$., nem da cor da pele dos participantes, $F(1,33)<1$, ns., sobre o preconceito automático. Este resultado é consistente com dados de outros estudos realizados nos EUA (Wittenbrink, Judd \& Park, 1997, 2001b), mas diferente dos resultados obtidos por Fazio et al. (1995), também nos EUA, que encontram um padrão diferente nas respostas dos negros a testes de preconceito implícito, ou seja, os negros apresentam preconceito automático contra os brancos.

Para verificarmos o efeito do contexto de resposta sobre o preconceito automático realizamos uma ANOVA com medidas repetidas, tomando o priming (Igualitário Formal/ Igualitário Solidário/ Meritocracia Competitiva Individualista) como variável inter-participantes e o tipo de associação (Compatíveis vs. "incompatíveis") como variável independente intra-participantes. A variável dependente foi a latência de resposta.

Primeiramente verificamos que o efeito principal do priming não foi significativo, $F(2,29)=1.82, p=18$. No entanto, o efeito principal do tipo de associação (efeito IAT) foi novamente significativo, $F(1,32)=7.13, p<.01$. Esse resultado mais uma vez confirma os pressupostos teóri- 
Lima, M.E.O., Machado, C., Ávila, J., Lima, C., \& Vala, J. (2006). Normas Sociais e Preconceito: O Impacto da Igualdade e da Competição no Preconceito Automático Contra os Negros.

cos de Greenwald e Banaji (1995), pois indica que as associações "compatíveis" (Brancos + Coisas Positivas vs. Negros + Coisas Negativas) são reconhecidas mais rapidamente $(M=1128.59 \mathrm{~ms}$., $D P=161.7 \mathrm{Oms}$. $)$ do que as associações «incompatíveis» (Negros + Coisas Positivas vs. Brancos + Coisas Negativas) $(M=1286.79 m s ., D P=$ $291.81 \mathrm{~ms}$.).

Todavia, na direção das nossas hipóteses, este efeito só faz sentido à luz da interação com o priming das normas sociais, que novamente foi significativa, $F(2,32)=3.59$, $p$ $<$.05. Como podemos ver na Tabela 3 , o contexto da meritocracia competitiva produz grande ativação preconceito automático; enquanto que o contexto igualitário solidário implica na anulação do preconceito automático. Este resultado pode ser melhor visualizado na Figura 2.

Tabela 3

Médias e Desvios Padrões (nos parêntesis) Latência de Resposta (em milésimos de segundos) nas Associações "Compatíveis" e "Incompatíveis" em Função do Priming $(n=35)$

\begin{tabular}{lll}
\hline Priming/Contexto & $\begin{array}{l}\text { Associações } \\
\text { Incompatíveis }\end{array}$ & $\begin{array}{l}\text { Associações } \\
\text { Compatíveis }\end{array}$ \\
\hline Meritocracia Competitiva & $\begin{array}{l}1453.45_{\mathrm{a}} \\
(188.10)\end{array}$ & $\begin{array}{l}1102.39_{\mathrm{b}} \\
(176.57)\end{array}$ \\
\hline Igualitário Formal & $\begin{array}{l}1243.95_{\mathrm{b}} \\
(251.05)\end{array}$ & $\begin{array}{l}1138.56_{\mathrm{b}} \\
(126.54)^{\circ}\end{array}$ \\
\hline Igualitário Solidário & $\begin{array}{l}1162.98_{\mathrm{b}} \\
(247.74)\end{array}$ & $\begin{array}{l}1144.81_{\mathrm{b}} \\
(188.12)\end{array}$ \\
\hline Total & 1286.79 & 1128.59
\end{tabular}

Nota. Médias com letras diferentes são significativamente diferentes (Student Nerman-Keuls, $p<.05$ )

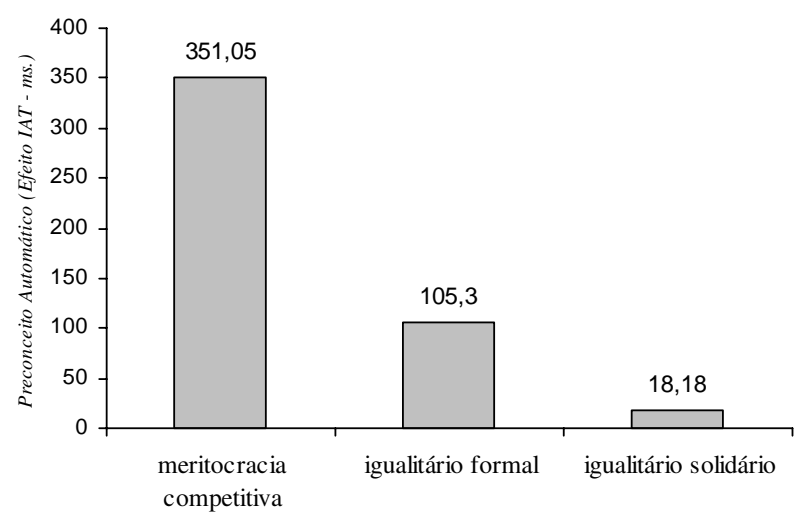

Figura 2. Efeito IAT (latência de resposta para as associações "incompatíveis" - latência de resposta para as associações compatíveis).

Na figura 2 apresentamos os escores do "efeito IAT". Por meio de um teste $\mathrm{t}$ de Student, no qual tomamos o zero (ausência de preconceito automático) como critério, podemos ver que existe preconceito automático no contexto da meritocracia competitiva ${ }^{7}$. Este preconceito se torna mais fraco, ainda que permaneça existindo no contexto da igualdade formal ${ }^{s}$. No entanto, como esperávamos, o contexto da igualdade solidária foi efetivo na anulação do preconceito automático contra os Negros ${ }^{9}$.

\section{Discussão Geral}

O objetivo dos três estudos apresentados foi demonstrar que a ativação automática do preconceito depende das normas sociais ou dos contextos que estejam salientes no momento da resposta. Para consecução deste objetivo introduzimos, antes de um teste já clássico na análise do preconceito automático (O Implicit Association Test), um priming normativo. As nossas hipóteses principais referiam-se à inibição da ativação automática quando do prime Igualitário e à facilitação da ativação automática quando do prime da Competição. No primeiro estudo os resultados encontrados confirmaram as nossas hipóteses referentes ao papel da norma da competição individualista. Vimos que a ativação automática do preconceito é mais forte entre os participantes que foram levados a pensar na competição. O contexto igualitário, por sua vez, não se diferenciou da condição neutra. O que deixou claro para nós que pensar na igualdade em termos formais ou em vida extraterrestre surte o mesmo efeito na inibição do preconceito automático.

No segundo estudo, seguindo pressupostos de alguns autores que têm analisado a ambigüidade da igualdade e com base nos fracos resultados obtidos com o prime igualitário no estudo 1, analisamos as representações sociais que são construídas sobre a igualdade. Neste estudo constatamos a polissemia da igualdade. Destacamos dois núcleos centrais nas visões de igualdade: um que entende a igualdade como igualdade de direitos e deveres, num sentido mais formalista e outro que concebe a igualdade em termos de uma ética das relações sociais, num sentido mais solidário e inclusivo. Este sentido mais social da igualdade (equidade) foi utilizado como prime no terceiro estudo.

Finalmente no terceiro estudo conseguimos anular o preconceito automático contra os Negros no contexto da igualdade solidária. Nesta condição não se verificou o efeito IAT, que novamente se manteve mais forte na condição de competição.

De uma maneira geral, os resultados obtidos nos três estudos indicam duas coisas importantes. Primeiro, que existe preconceito automático contra os negros (o efeito IAT foi significativo nos estudos 1 e 3), mesmo num ambiente universitário e em uma cidade em que $80 \%$ da população é negra, como é o caso de Salvador. Segundo, o preconceito automático não acontece num vácuo social e não é meramente um resíduo indesejável e inevitável do funcionamento cognitivo humano, como afirma grande parte dos autores da psicologia social que estudam o tema
${ }^{7}$ Teste $t$ contra zero (ausência de efeito), $\mathrm{t}(10)=4.93, p$
$<.001$.
${ }^{8}$ Teste $\mathrm{t}$ contra zero, $\mathrm{t}(12)=2.45, p<.05$

${ }^{9}$ Teste $t$ contra zero, $t(11)<1, n s$. 
(Bargh, 1999; Greenwald \& Banaji, 1995; Hamilton, 1981; Wegner \& Bargh, 1998).

Os nossos resultados indicam que o preconceito automático é fortemente influenciado pelos contextos de resposta. De tal modo que, o simples fato de levar as pessoas a pensarem sobre a competição as tornam mais preconceituosas; ao passo que quando são instadas a pensar sobre a igualdade solidária o preconceito inconsciente contra os negros desaparece.

Esses resultados, no nosso ponto de vista, possuem relevância social para a elaboração de estratégias de combate ao preconceito. Além de os dados obtidos sinalizarem a importância dos fatores situacionais no preconceito, o que implica uma contribuição na crítica às análises do preconceito centradas estritamente nos fatores de personalidade, impulsos biológicos ou em vieses cognitivos universalistas, tão comuns na psicologia social (ver Duckitt, 1992); os dados obtidos ainda podem contribuir, se integrados a uma rede de outros esforços e estudos de entendimento do tema, para a elaboração de estratégias multiculturais menos ingênuas e mais efetivas no combate ao preconceito racial.

De fato, se concebermos o preconceito racial à semelhança de icebergs, que possuem uma parte externa pública e outra, quem sabe maior, interna e oculta, para destruir este iceberg ou combater o preconceito é necessário adotar, além das tão comuns e às vezes caricatas estratégias de controle, sanção e reeducação das expressões públicas de preconceito, também modos de inibição e eliminação das facetas sub-reptícias e ocultas que subjazem e mantêm o padrão hipócrita das expressões públicas de preconceito.

Assim, quando formos analisar episódios racistas, com aqueles que implicaram na morte Diallo e Flávio, dentre tantos outros, devemos olhar para eles não apenas com os olhos de quem condena uma polícia violenta e racista; mas, sobretudo, com a visão de que os comportamentos e práticas dos atores sociais são fomentados e gerados por teias ideológicas mais amplas e complexas que precisam também, juntamente com as práticas dos atores sociais, ser repensadas e transformadas. Caso contrário teremos sempre uma sociedade sedimentada na hipocrisia, que pensa uma coisa e diz e faz outra e que quando encontra um contexto normativo apropriado, que possa justificar ou disfarçar suas práticas, se expressa violentamente contra as minorias.

\section{Referências}

Abbagnano, N. (1998). Dicionário de Filosofia. São Paulo, SP: Martins Fontes.

Bargh, J. A. (1989). Conditional automaticity: Varieties of automatic influence in social perception and cognition. In J. S. Uleman \& J. A. Bargh (Eds.), Unintended thought (pp. 3-51). Nova York: Guilford Press.

Bargh, J. A. (1994). The four horsemen of automaticity: Awareness, intention, efficiency, and control in social cognition. In R. S. Wyer \& T. K. Srull (Eds.), Handbook of social cognition (2nd ed., Vol. 1, pp. 1-40). Hillsdale, NJ: Erlbaum.
Bargh, J. A. (1999). The cognitive monster: The case against the controllability of automatic stereotype effects. In S. Chaiken \& Y. Trope (Eds.), Dual-processes theories in social psychology (pp. 361-382). Nova York: The Guilford Press.

Bargh, J. A., Chen, M., \& Burrows, L. (1996). Automaticity of social behavior: Direct effects of trait construct and social stereotype activation on action. Journal of Personality and Social Psychology, 71, 230-244.

Billig, M. (1984). Political ideology: Social psychology aspects. In H. Tajfel (Ed.), The social dimension: European studies in social psychology (Vol. 2, pp. 446-465). London: Cambridge University Press.

Correia, I., Brito, R., Vala, J., \& Perez, J. (2001). Normes antiracistes et persistance du racisme flagrant: Analyse comparative des attitudes face aux Tziganes et face aux noirs au Portugal. Lisbon, Portugal: Centro de Investigação e Intervenção Social do ISCTE. Unpublished manuscript.

Crandall, C. S., Eshleman, A., \& O’Brien, L. (2002). Social norms and the expression and supression of prejudice: The struggle of internalisation. Journal of Personality and Social Psychology, 82, 359-378.

Devine, P. G. (1989). Stereotypes and prejudice: Their automatic and controlled components. Journal of Personality and Social Psychology, 56, 1, 1-18.

Devine, P. G., Plant, E. A., Amodio, D. M., Harmon-Jones, E., \& Vance, S. L. (2002). The regulation of explicit and implicit racial bias: The role of motivations to respond without prejudice. Journal of Personality and Social Psychology, 82(5), 835-848.

Dovidio, J. F. (2001). On the nature of contemporary prejudice: The third wave. Journal of Social Issues, 57, 829-849.

Dovidio, J. F., Kawakami, K., Johnson, C., Johnson, B., \& Howard, A. (1997). On the nature of prejudice: Automatic and controlled process. Journal of Experimental Social Psychology, $33,510-540$.

Dubois, N. (2003). (Ed.). A sociocognitive approach to social norms. London: Routledge.

Duckitt, J. (1992). A historical analysis and integrative framework. American Psychologist, 47, 1182-1193.

Fazio, R. H., Jackson, J. R., Dunton, B. C., \& Williams, C. J. (1995). Variability in automatic activation as an unobtrusive measure of racial attitudes: A bona fide pipeline? Journal of Personality and Social Psychology, 69, 1013-1027.

Fundação Perseu Abamo. (2003, 06 de outubro). Discriminação racial e preconceito de cor no Brasil. Retirado em 20 de agosto de 2004 do Portal Mundo Negro, em http:// www.mundonegro.com.br/noticiais/index.php?

Gaertner, S. L., \& Mclaughlin, J. P. (1983). Racial stereotypes: Associations and ascriptions of positive and negative characteristic. Social Psychology Quarlerly, 46, 23-30.

Goodwin, S. A., Gubin, A., Fiske, S. T., \& Yzerbyt, V. Y. (2000). Power can bias impression processes: Stereotyping subordinates by default and by design. Group Processes and Intergroup Relations, 3, 227-256.

Greenwald, A. G., \& Banaji, M. R. (1995). Implicit social cognition: Attitudes, self-esteem, and stereotypes. Psychological Review, 102, 4-27.

Greenwald, A. G., McGhee, D. E., \& Schwartz, L. K. (1998). Measuring individual differences in implicit cognition: The implicit association test. Journal of Personality and Social Psychology, 74, 1464-1480. 
Lima, M.E.O., Machado, C., Ávila, J., Lima, C., \& Vala, J. (2006). Normas Sociais e Preconceito: O Impacto da Igualdade e da Competição no Preconceito Automático Contra os Negros.

Hamilton, D. (1981). Cognitive representations of persons. In E. Higgins, C. Herman \& M. P. Zanna (Eds.), Social cognition. The Ontario Symposium on Personality and social Psychology (Vol. I). Hillsdale, NJ: Erlbaum.

Hertel, G., Aart, H., \& Zeelenberg, M. (2002). What do you think is 'fair'? Effects of ingroup norms and outcome control on fairness judgments. European Journal of Social Psychology, 32, 327-341.

Hertel, G., \& Kerr, N. L. (2001). Priming in-group favouritism: The impact of normative scripts in the minimal group paradigm. Journal of Experimental and Social Psychology, 37, 316-324.

Jetten, J., Spears, R., \& Manstead, A. S. R. (1996). Identity threat and prototypicality: Combined effects on intergroup discrimination and collective self-esteem. European Journal of Social Psychology, 27, 635-657.

Katz, I., \& Hass, R. G. (1988). Racial ambivalence and American value conflict: correlational and priming studies of dual cognitive structures. Journal of Personality and Social Psychology, 55, 893-905.

Lima, M. E. O. (2003). Normas sociais e racismo: Efeitos do individualismo meritocrático e do igualitarismo na infra-humanização dos Negros. Tese de Doutorado não-publicada, Instituto Superior de Ciências do Trabalho e da Empresa, Lisboa, Portugal.

Lima, M. E. O., \& Vala, J. (2002). Individualismo meritocrático, diferenciação cultural e racismo. Análise Social, 37, 181-207. Lisboa, Portugal.

Lima, M. E. O., \& Vala, J. (2004a). Serão os estereótipos e o preconceito inevitáveis? O monstro da automaticidade. In M. E. O. Lima \& M. E. Pereira, Estereótipos, preconceito e discriminação: Perspectivas teóricas e empíricas (pp. 41-68). Salvador, BA: Editora da Universidade Federal da Bahia.

Lima, M. E. O., \& Vala, J. (2004b). Sucesso social, branqueamento e racismo. Psicologia: Teoria e Pesquisa, 20(1), 11-19.

Maio, G. R., Olson, J. M., Allen, L., \& Bernard, M. M. (2001). Addressing discrepancies between values and behavior: The motivating effect of reasons. Journal of Experimental and Social Psychology, 37, 104-117.

Major, B., Gramzow, R. H., McCoy, S. K., Levin, S., Schmader, T., \& Sidanius, J. (2002). Perceiving personal discrimination: The role of group status and legitimizing ideology. Journal of Personality and Social Psychology, 82, 269-282.

Minard, R. D. (1952). Race relations in the Pocahontas coal field. Journal of Social Issues, 8, 29-44.

Pettigrew, T. F. (1958). Personality and social-cultural factors in intergroup attitudes: A cross-national comparison. Journal of Conflict Resolution, 2, 29-42.

Posner, M. I., \& Snyder, C. R. R. (1975). Attention and cognitive control. In R. L. Solso (Ed.), Information processing and cognition: The Loyola symposium (pp. 55-85). Hillsdale, NJ: Erlbaum.

Rokeach, M. (1968). Beliefs, attitudes and values. San Francisco, CA: Jessey-Bass.

Schwartz, S. H. (1996). Value priorities and behaviour: Applying a theory of integrated value systems. In C. Seligman, J. M. Olson \& M. P. Zanna (Eds.), The Psychology of values: The Ontario Symposium (Vol. 8, pp. 1-24). Mahwah, NJ: LEA.

Sherif, M. (1936). The Psychology of social norms. Nova York: Harper and Row.

Sherif, M. (1967). Group conflict and cooperation: Their social psychology. London: Routledge and Kegan Paul.

Sherif, M., \& Sherif, C. W. (1953). Groups in harmony and tensions: An integration of studies on intergroup relations. Nova York: Octagon.
Turra, C., \& Venturi, G. (1995). Racismo cordial: A mais completa análise sobre preconceito de cor no Brasil. São Paulo, SP: Ática.

Vala, J., Brito, R., \& Lopes, D. (1999). Expressões dos racismos em Portugal: Perspectivas psicossociológicas. Lisboa, Portugal: Instituto de Ciências Sociais da Universidade de Lisboa.

Vala, J., Lima, M., \& Lopes, D. (2002). Social values, prejudice and solidarity in the European Union. In W. Arts \& L. Halman (Eds.), European values at the end of the millenium. Leiden, Holland: Brill.

Wegner, D. M., \& Bargh, J. A. (1998). Control and automaticity in social life. In D. T. Gilbert, S. T. Fiske \& G. Lindsey (Eds.), Handbook of social Psychology (4nd ed., Vol. 2, pp. 446-496). New York: McGraw-Hill.

Wieviorka, M. (2002). A diferença. Lisboa, Portugal: Fenda.

Wittenbrink, B., Judd, C. M., \& Park, B. (1997). Evidence for racial prejudice at the implicit level and its relationship with questionnaire measures. Journal of Personality and Social Psychology, 72, 262-274.

Wittenbrink, B., Judd, C. M., \& Park, B. (2001a). Evaluative versus conceptual judgments in automatic stereotyping and prejudice. Journal of Experimental Social Psychology, 37, 244252 .

Wittenbrink, B., Judd, C. M., \& Park, B. (2001b). Spontaneous prejudice in context variability in automatically activated attitudes. Journal of Personality and Social Psychology, 81, 815827
Recebido: 27/05/2005 1 revisão: $15 / 07 / 2005$ Aceite final: 10/10/2005 